\title{
Doctor Manuel Solis de Ovando: Mártir del tifus exantemático
}

\author{
ENRIQUE LAVAL R.*
}

\section{Doctor Manuel Solís de Ovando: Martir of the Exantematic Typhus}

"Nada en la historia se ha hecho perdurable y memorable sin sufrimiento ni dolor".

Una hermosa placa de bronce colocada a la entrada de uno de los pabellones del antiguo Instituto de Higiene, después sede de la Dirección General de Sanidad, recordaba bajo el epígrafe "a los que sobreviven entre nosotros porque murieron por nosotros", a quienes rindieron su vida en defensa de la salud de nuestros conciudadanos. ${ }^{1}$

Entre ellos figuran don Rómulo Figueroa, joven estudiante de Medicina, que falleció en San Felipe el 17 de enero de 1887, víctima del cólera, "por su abnegación y en servicio de sus semejantes". También, don Francisco $2^{\circ}$ Fonck, después de estar atendiendo enfermos de cólera en Santiago, contrajo la enfermedad y falleció el 8 de mayo de aquél año, "perdiéndose un joven lleno de inteligencia y de porvenir, que habría sido de grande utilidad en su carrera de médico, cuyo título debía recibir pronto". ${ }^{2}$

Sin embargo, en aquella lista no está el estudiante de Medicina don Marcos Macuada Ogalde, quien murió de fiebre amarilla, durante la epidemia de Tocopilla, en 1912 y del que hemos escrito anteriormente.

El sacrificio de estos estudiantes fue antecedido por el del doctor don Manuel Solís de Ovando, "inmolado en el valle del Choapa en 1865, combatiendo el tifus exantemático". ${ }^{1}$

Al cabo de 10 años de su deceso, el profesor Adolfo Valderrama decía en la Academia de Bellas Letras: "no vengo a pintaros un sabio, vengo a retrataros a un mártir; no vengo a hacer la historia de una de esas vigorosas inteligencias que dejan huellas profundas en los anales de la ciencia, vengo a presentaros el rostro ensangrentado de uno de esos nobles viajeros de la existencia que pagan con su propia vida su amor por la ciencia y la humanidad".

El doctor Solís de Ovando nació en Santiago, el 10 de junio de 1833, realizando sus estudios de humanidades en el Instituto Nacional. Valderrama lo describe "de estatura mediana, con su cabeza cubierta de cabellos lisos y negros, dejando descubierta una frente espaciosa, debajo de pobladísimas cejas brillaban sus grandes ojos negros, llenos de expresión, su nariz corta pero recta y bien formada, sus labios gruesos y contraídos daban a aquel rostro, más bien redondo que oval, una singular expresión de malicia, que contrastaba con la bondad de su alma".

Finalizados sus estudios en el Instituto Nacional, el joven Solís decidió estudiar Medicina. Profundamente religioso y poseedor de una gran cultura clásica, era un gran charlista. Desde que se incorporó a los estudios médicos, se apasionó por la Botánica, sintiendo la necesidad de conocer las plantas medicinales de Chile, emprendiendo con laudable empeño, el estudio de la flora nacional, formando un herbario bastante considerable, consultado siempre con interés

Solís de Ovando se recibió el 12 de mayo de 1858. $\mathrm{Su}$ tesis de médico versó sobre el "Aumento de volumen del corazón en la endocarditis", de acuerdo con el gran interés que mostró durante su carrera por el estudio de las afecciones del corazón, destacando por la facilidad con que diagnosticaba las valvulopatías, siendo llamado por sus compañeros con el apodo de "Monsieur Bouillaud", el ilustre maestro de la Escuela de Medicina de París. ${ }^{4,5}$

Ejerció durante poco tiempo en Santiago, incorporándose a la Sociedad de Farmacia, con un trabajo sobre los Baños de Catillo. Fue miembro de la Hermandad de Dolores.

Después el doctor Solís de Ovando se fue a Talca, donde "ejerció su profesión con aquella prudencia y seriedad que constituían el fondo de su carácter y que son la garantía del éxito". Pero no podía quedar en esa provincia mucho tiempo. Santiago era para Solís un centro necesario donde encontraba todo para la actividad de su espíritu, ejerciendo su profesión con dignidad y verdadera ciencia.

Solís no era sólo una distinguida inteligencia; "brillaba igualmente, como todos los grandes médicos, por las cualidades del corazón".

En octubre de 1864, una epidemia de tifus exantemático diezmaba las poblaciones del norte de la República. Solicitado para participar en la gran campaña para combatir la enfermedad, no vaciló un instante en aceptar aquella misión. Por Decreto Supremo del 3 de noviembre de 1864 , se le hizo entrega de $\$ 517$, para adquirir medicamentos y fue trasladado al Valle del Choapa. Falleció presa de la misma epidemia que había ido a combatir con tanta abnegación, en Salamanca, el 11 de febrero de 1865 y a la edad de 33 años. ${ }^{5}$

El doctor Valderrama anota que "si él no pudo avanzar a la ciencia por haber muerto demasiado joven, vivió bastante para hacerla respetar con su conducta, para honrarla con su valor, para santificarla con su muerte". 4

Una corta calle de la comuna de Providencia en Santiago, cerca del Hospital Luis Calvo Mackenna, recuerda con su nombre a este mártir de la medicina chilena.

\section{Bibliografía}

1.- Laval M E. Marcos Macuada. An Chil Hist Med 1962; 1: 31 .

2.- El Mercurio de Valparaíso. 26 de enero de 1887 y 9 de marzo de 1887

3.- Laval R E. Fiebre amarilla en Chile. Rev Chil lnfect 1986; 3: 86.

4.- Valderrama A. Manuel A Solís. Rev Méd Chile 1875; 7: 5 .

5.- Laval M E. Notas sobre los médicos en Chile. Letra 5 (inédito). 